\title{
How midwifery students experience learning conditions in labor wards
}

\author{
Anne Brunstad ${ }^{* 1}$, Tove Giske ${ }^{2}$, Esther Hjälmhult ${ }^{1}$ \\ ${ }^{1}$ Faculty of Health and Social Sciences, Bergen University College, Bergen, Norway \\ ${ }^{2}$ VID Specialized University, Bergen, Norway
}

Received: October 19, 2015

DOI: $10.5430 /$ jnep.v6n4p136
Accepted: January 11, $2016 \quad$ Online Published: January 28, 2016

URL: http://dx.doi.org/10.5430/jnep.v6n4p136

\begin{abstract}
Midwives are responsible for the well-being of women and babies during labor and birth. Learning midwifery is complex and challenging, and how students are welcomed into the labor wards affects learning. This study aimed to identify and explain the conditions that affected midwifery students' learning in labor wards and their consequences. We used classical grounded theory to analyze longitudinal data from 15 individual and three focus group interviews of 10 postgraduate midwifery students in Norway. The key conditions identified that affect the learning outcomes of midwifery students were related to the students' relationships with midwives, the students themselves and the learning arena. Tailored assignments from midwives enhanced students' learning and apprehensive relationships with midwives inhibited learning. Midwives played a key role in facilitating students' learning by tailoring their learning opportunities and debriefing after challenging incidents and thus smoothed how students' emotions affect their self-esteem and learning process.
\end{abstract}

Key Words: Midwife, Student, Experience, Learning, Labor ward, Grounded theory

\section{INTRODUCTION}

Working as a midwife in labor wards is complex and insecure. The labor process is unpredictable and can rapidly become complicated. The midwife is responsible for the life and health of both the mother and the baby. The time slot is tight, and misjudgments can have serious consequences for the baby. The distinctive character of labor wards affects how midwifery students learn. ${ }^{[1,2]}$

Davies and Atkinson ${ }^{[3]}$ reported that students faced challenges in moving from the role of independent nurse to midwifery student. The coping strategies midwife students used involved reverting to routine nursing activities. Midwifery students can have several sources of stress in labor wards, such as the organization of the learning environment, the need to balance the demands of studying and home life and the need to deal with life-and-death situations. ${ }^{[4]}$ Stress is defined as a relationship between the person and the environment that the person considers taxing or exceeding his or her resources and endangering his or her well-being. ${ }^{[5]}$ Stress may lead to both eustress, a positive response to the stressor, and distress, which means that the person cannot cope with or resolve the situation. Whether a stimulus creates distress or eustress depends on the person's appraisal of the situation. ${ }^{[6]}$

Several studies have revealed that acceptance into the community of practice is important for the learning of midwife students. ${ }^{[7-9]}$ Midwifery students strive to initiate and de-

\footnotetext{
*Correspondence: Anne Brunstad; Email: anne.brunstad@hib.no; Address: Faculty of Health and Social Sciences, Bergen University College, Bergen, Norway.
} 
velop professional and personal relationships with midwives; fitting in is important. ${ }^{[10]}$ Begley ${ }^{[1]}$ described the structure of midwifery in hospitals as hierarchical and found that the senior students felt they had to copy the behavior of senior midwives in their interaction with new students to be accepted by the senior midwives. Hunter reported that midwifery students rarely questioned the midwives' rules because senior midwives assessed their clinical competence. ${ }^{[12]}$ Midwives are important in developing midwifery students' confidence in practice, ${ }^{[13]}$ and in ensuring that they are competent. ${ }^{[14]}$ Midwives are also important role models for midwifery students, both positively and negatively. ${ }^{[15-17]}$

\section{Background}

Norway has a two-year postgraduate program in midwifery. The admission requirements are a BSc in nursing and one year of full-time work as a registered nurse. The program comprises 40 weeks of theoretical studies and 40 weeks of clinical studies. The students have clinical studies in prenatal care, in the community and in hospitals, as well as in labor wards and postnatal care in the hospitals.

Labor wards are organized into two different models of care in Norway: low-risk and high-risk wards. Low-risk wards are midwifery led and women with no risk factors during pregnancy are selected to deliver there. These wards have a minimum of technical equipment. The high-risk ward has women with various complications, such as diabetes or preeclampsia, requiring epidural analgesia or inducing labor. Midwives have to master various types of high-technology equipment.

The midwives work autonomously in both models of care, and obstetricians are called when the midwives identify deviation. Since the high-risk ward has more intervention, such as vacuum extraction and forceps, obstetricians are more often present.

Midwifery students are required to be the main birth attendant in at least 50 normal births. ${ }^{[18]}$ The clinical studies include four modules, and students have to pass each before starting the next. Each student is assigned two midwife mentors. In addition, one contact midwife is responsible for organizing the clinical study of students and linking the students, mentor midwives and lecturers. The contact midwife and the mentor midwives are responsible for assessing and evaluating the student.

The lecturers have weekly telephone or e-mail contact with students and the contact midwife. One day each semester, the lecturers meet all the students and the contact midwife in their placement and discuss and analyze their clinical experiences from a theoretical perspective.

Published by Sciedu Press
During their clinical studies, students have several academic writing assignments, intended to link students' clinical experiences with theory and research findings. This requires students to find and assess relevant research articles related to their experiences. The lecturers are responsible for supervising the academic writing in the placement period. The midwife mentors and contact midwife have access to the final academic papers. Students have to pass the writing assignments to pass the clinical placements.

Brunstad and Hjälmhult ${ }^{[19]}$ found that the main concern of midwifery students in labor wards were how to gain access to learning experiences and that student wanted to demonstrate their suitability for this profession to their mentor midwives. The grounded theory of building relationships explains how midwifery students address this concern in labor wards and encompasses three phases: controlling vulnerability, cultivating trust and obtaining acceptance.

More in-depth knowledge is needed to improve understanding of the complexity of the learning process of midwifery students in labor wards. The aim of this study was to enhance knowledge of the conditions affecting the learning of midwifery students' in labor wards and the consequences of such conditions. Understanding students' experiences can be useful for the education of midwifery students, both for midwives in clinical practice and lecturers.

\section{METHODS}

\subsection{Design}

We used classical grounded theory, because this method is useful for explaining social phenomena, processes and conditions within a specific field. ${ }^{[20,21]}$ We collected data by interviews, coded and analyzed data concurrently and sought the main concern, strategies and conditions in a constant comparison process.

\subsection{Participants}

Participants were recruited as follows: 29 students at a Norwegian University College entering the first semester of the midwifery training program received oral and written information about the study and an invitation to participate. Ten of these responded by e-mail to the first author and agreed to participate in the study; one dropped out in the fourth semester. The relationships between one of the authors (a lecturer) and the participants were distant, because other lecturers had the contact with these students in their clinical practice. The two other authors did not work in the midwifery program. All participants were women 26-39 years old. The participants had clinical placements at seven hospitals. Each participant had one period of practice in a low-risk labor ward and three periods in high-risk labor wards. 


\subsection{Data collection and analysis}

In this longitudinal study, we conducted 10 individual interviews after the participants' first semester. In the third semester, the participants were divided into two focus groups, and in the fourth semester, five participated in individual interviews and four in a focus-group. Data comprised 15 individual interviews and three focus-group interviews. The interviews, lasting 30-90 minutes, took place after clinical studies when the participants were back in school. The interviews started with an open question about the participants' learning experiences in practice. We asked prompting questions to minimize misunderstanding, such as: "Could you please say more about or describe...?". We used individual interviews to obtain more in-depth information and focusgroup interviews to provide a forum in which participants could share and discuss their experience and thus bring forth diverse views and experiences. ${ }^{[22]}$

The first author tape-recorded the interviews and transcribed them verbatim. The analysis started after the first interview with open coding, by hand, in which we successively compared incident to incident and codes with other codes for similarities and differences to generate the properties and dimensions of the categories. ${ }^{[20]}$ The first author wrote memos throughout the study. We searched for patterns and connections in the data, which we explored further in subsequent interviews. When we identified the main concern and core category, we moved on to selective coding until the codes with strategies and conditions were saturated. Theoretical coding wove the grounded theory together so we understood how the condition and concepts were related to each other and what the consequences would be. ${ }^{[21]}$

\subsection{Ethical issues}

The Norwegian Social Sciences Data Services approved the study (NSD\# 19854). After receiving oral and written information about the study, students replied by e-mail to the first author, and this was considered written, informed consent. Participants could withdraw at any time; the data were treated confidentially. Participants' confidentiality was ensured by giving interview participants a pseudonym in transcription and by not revealing the cohort to which the students belonged, but the data collection started after 2009.

\section{Findings}

Three main conditions emerged as influencing the participants' learning in labor wards. The conditions were related to the midwives, the participants themselves and the learning arena. The participants noticed from the beginning of their placement the responsibility and autonomy the midwives had in the labor wards. They witnessed how the midwives cared for and followed the women during the labor process and how they carefully evaluated the need to call in obstetricians if anything deviated from normality. This set the standard for the competencies the students struggled to develop in their placements. The participants' emotions inhibited and facilitated their learning and affected their self-esteem. Quotes from the two models of care and various semesters are used to indicate participants' experiences. The names in quotes are pseudonyms.

\subsection{Conditions related to the midwives}

During their clinical studies, the participants were in the midwives' territory. The midwives set the tone and were gatekeepers for more or less helpful learning opportunities. Although the participants had trained their practical skills at the University College, the most important learning occurs in authentic situations guided by midwives.

Some conditions enhanced participants' learning, such as midwives making them feel welcome and expected. When participants came back to the ward and midwives remembered their names, they felt valued. Another condition conducive to participants' learning was that the midwives were interested in knowing the individual participants and in including them in the work. Midwives having clear and appropriate expectations of the students and giving them specific responsibilities and tasks they could master facilitated learning. Having midwives who trusted them and who remained in the background, ready to support if the situation became too complex, provided students with excellent learning conditions. Sara:

The midwife said: "You may go into the labor room and turn on the cardiotocograph". I was given the opportunity to establish the first contact. Then the midwife entered and greeted the woman. She considered me as an equal and pushed me a bit forward without this being conspicuous. It was great. (Sara, high-risk ward, first semester)

Another condition that facilitated learning was when the mentor selected suitable cases and tailored the learning situations for the participants, giving them appropriate tasks with discrete supervision. Participants could best integrate the learning when the midwives guided and counseled them through the process. This gave them confidence, which in turn encouraged them to continue taking on the gradually more complex tasks. When they became more experienced, the participants could benefit from seeing various ways to manage a situation and could deal with situations demanding more complex proficiencies. Such skill learning could be 
related to practices minimizing trauma to the perineum, to inserting a urethral catheter or to vaginal examination, Ann:

I managed to identify the orifice of the uterus. I think it depends on how the midwife behaves in the situation. The situation was calm, so I had the opportunity to concentrate; I was not stressed. The orifice of the uterus was dilated $2-3 \mathrm{~cm}$. (Ann, high-risk ward, first semester)

The participants considered the midwives who took time to talk with them about their experiences during the day and give them feedback to be good supervisors.

Unfortunately, the participants did not receive such feedback from midwives regularly. Other conditions inhibiting participants' learning included participants' and midwives' personalities being mismatched or when they did not know each other well enough. In the beginning, participants appreciated following one midwife, since seeing different ways of doing the same thing confused the novices. Likewise, midwives interfering too rapidly in a situation or pushing the participants into circumstances for which they were not ready became obstacles for learning. In general, learning conditions were difficult when midwives were stressed.

Poor relationships and professional questions and tasks the participants could not master gave rise to an unpleasant feeling of exposure. When participants were asked testing questions in front of the women or couple or when it became apparent that they lacked knowledge or practical skills, they felt that this jeopardized their relationships with both the midwife and the woman. In the beginning, some participants insecurity increased when the midwife asked: "Haven't you learned that?" Nor did they like it when midwives asked controlling questions outside the labor room such as: "Have you done that?" The participants perceived this as a sign of mistrust. A feeling of being tested inhibited learning, as Vigdis expressed:

I did not like the questioning in the labor room; they can ask me outside. If I am performing a vaginal exploration and answer incorrectly, I feel the women's trust in me is weakened. It is easier to be asked questions I can answer. (Vigdis, low-risk ward, third semester)

Some midwives gave praise in a subordinate clause and always focused on what the participants should have done better. The participants also reported situations in which the midwives had humiliated and mocked them, which undermined all positive learning. One participant experienced this in the birth room when the midwife said:

Published by Sciedu Press
Aren't you a nurse? Aren't you able to insert a urinary catheter into the women? (high-risk ward, fourth semester)

\subsection{Conditions related to the students}

Most participants found the transition from being a nurse to becoming a midwifery student challenging. They found it stressful to move back to a lower competence level as a novice, and they had cope with this. The lack of mastery associated with the student role and the unclear expectations from midwives made their clinical modules demanding. Some participants made great demands on themselves, and some were perfectionists with a high fear of failure, which was distressing. The complexity of the midwifery profession and the practical tasks made some of them embarrassed when they could not coped. Participants who were used to coping well in life did not expect to experience such lack of mastery. Rita who experienced an unexpected situation said:

What should I do now? I have no strategy for mastering this. I am not a stressed person. I feel I am usually calm and have control over myself. (Rita, low-risk ward, third semester)

Participants talked about how their feelings affected their ability to learn in labor wards. Feelings of joy, satisfaction and excitement as well as of guilt, embarrassment, fear and heart palpitation were related to their relationship with the midwife the birthing woman and the various tasks or incidents in the ward. Participants could interpret unpleasant emotions such as embarrassment or feeling stupid as expecting that the situation could be handled better. Some started to doubt themselves and became insecure. The strongest emotions were triggered in acute situations. Ine:

It was terrible, the most awful experience I have had, I wanted to vomit, I could hardly remain standing. The others were occupied with the baby, and I stood with the mother. You have to watch the mother, the midwife said. I tried to see whether she was bleeding. I was not prepared for the baby's condition. (Ine, low-risk ward, third semester)

Since acute situations could cause unexpected physiological responses, it was particularly demanding for the participants to carry on with their tasks if they felt dizzy, shaky or sick or if their heart was racing and they were perplexed. Their feeling of responsibility for the mother and baby made them fear that they might have overlooked something or had done something wrong. This insecurity led to feelings of guilt. Katrine: 
I thought the baby was dead, everything happened so quickly. I was uncertain whether I had done something wrong that it was my fault. (Katrine, low-risk ward, first semester)

The result of this condition was growing awareness, which was considered useful, professionally and personally, particularly when the participants managed to keep cool and do what they were supposed to do and what they were told. In these situations, they gained confirmation that they had chosen the right profession. Kari:

It is wonderful to have been in this situation because, when I am stressed, I manage to do what I'm told. I manage to step out of myself. Afterwards, I learned a lot about myself; I am strong enough to become a midwife. (Kari, high-risk ward, fourth semester)

\subsection{Conditions related to the learning arena}

The labor wards are unique and intense, with unpredictable conditions for the mother and the baby. The participants had difficulty in making plans for learning because they did not know what they would encounter in the delivery room.

At low-risk wards, they were alone in the placement. They missed having classmates with whom they could copy and compare their learning outcomes, although some participants said that this made it easier to create their own identity as a midwife.

When a delivery ended in an acute situation, many professionals entered the scene and considerable information and instructions were given. Acute situations placed the participants in demanding learning situations in which they were not able to contribute, especially in the beginning. They dreaded acute situations, since these were difficult for them to understand and act upon. Since there was no debriefing after these acute situations, the participants were generally left alone to process the experience. Having other students around could help to process such situations. Occasionally, the midwives talked with participants afterwards.

Each birth was unique; however, following up of individual cases enabled them to discover differences and nuances, and they could increasingly prepare for future labor situations. As the participants became more experienced, they were also able to learn from acute situations. The pleasant emotions were often connected with normal births and mastery of the tasks in general and particularly in demanding situations. Randi:

When the baby was born, I coped with it better. It was very frightening. I learned to stretch my boundaries and remain focused on the situation, even though I did not have control. This is how one develops. (Randi, high-risk ward, forth semester)

Conditions in the learning arena inhibiting learning included participants feeling that they were in unfamiliar territory and experiencing insecure relationships. Some participants complained about the written assignment during their placements, since this was time consuming, and if they did not understand how to do the assignments or see the benefit, it became an extra burden in an already demanding placement. Lack of support from midwives who questioned the necessity of the academic writing undermined their motivation for this assignment. Bodil:

We could have spent more time learning about the midwifery profession; that would be useful for us. I'm not going to be a researcher. (Bodil, low-risk ward, fourth semester)

However, as the participants became more proficient, they discovered the benefits of the written assignments. The assignments helped some participants to process acute situations or other challenging experiences encountered in their clinical placements; others did not discover these benefits until the end of their fourth placement. Tone reflected on her experience with academic writing:

When I did the academic writing, I could consider the situation from many perspectives and become more conscious of my own reaction. (Tone, low-risk ward, first semester)

The optimal conditions that facilitated growing confidence and increased ability were when the students received tailored and specific expectations from midwives. After some time, participants experienced their learning as a quantum leap; they had gained a partial overview of and insight into midwifery and understood that they still had much to learn.

\section{Discussion}

We found that the conditions related to midwives, students and the learning arena could influenced the learning of midwifery students in clinical practice both positively and negatively. When the conditions were conducive to learning, participants experienced the stress of learning as eustress. However, the participants often experienced their learning as distress.

In the beginning of their placements, the participants preferred predictability related both to the allocated mentors and to the learning opportunities in the ward. Students find that adapting to the institutions' values and norms is more 
important than challenging them, ${ }^{[23]}$ for adopting traditional midwifery practices ${ }^{[16]}$ and for achieving competence ${ }^{[24]}$

When acute situations happen, especially in low-risk wards, the participants could be caught off guard. However, Bairds ${ }^{[25]}$ found that students experienced midwifery autonomy only in the midwife-led birthing units; autonomy was almost invisible in obstetrician-led units. Since the low-risk ward is midwife-led, placements in both low-and high-risk wards may have aided the participants in working as autonomous midwives and were therefore important in student education. Several participants experienced strong unexpected physiological responses and unpleasant emotions in acute and demanding situations. Our participants seemed to be more prepared for the pleasant emotions than the unpleasant and frightening ones. Their emotions both inhibited and facilitated heir learning. According to Folkman ${ }^{[5]}$ people may perceive similar situations differently. This may also correspond with Ursin and Eriksen ${ }^{[6]}$ who claim whether a stimulus is pleasant or threatening depending on the individual experience and expectation of coping. Bandura ${ }^{[26,27]}$ also claims that people's mastery expectations affect their ability and possibility to cope.

Some participants seem to have placed great demands on themselves in general and described themselves as perfectionists. Initially, some seemed to have unrealistic expectations regarding the complexity of the midwifery profession and their own energy, and they found themselves in a situation of distress in which the conditions in the placements exceeded their resources. These feelings could arise both in low and high-risk labor wards. Cavanagh and Snape ${ }^{[4]}$ also found that clinical placements create distress among midwifery students because they were exposed to "life-anddeath situations". Nevertheless, dealing with normal births as well as unexpected traumatic events, is a hallmark of the midwifery profession. Davies et al. ${ }^{[28]}$ also found that student midwives feeling unprepared led to traumatic experiences. It is therefore important to clarify expectations and emphasize for participants that the midwives are responsible for the birthing woman and baby, and the students may then obtain a sense of security. This may also relate to Begley, ${ }^{[29]}$ who asserted that when the environment appeared to focus on work rather than learning, students become frightened and unsure of themselves.

Khajehei et al. ${ }^{[30]}$ also described palpitations, fatigue and dizziness as responses among midwifery students. This can be interpreted as participants' perception of the learning situation as very stressful leading to cognitive activation and bodily stress, which Ursin and Eriksen ${ }^{[6,31]}$ would understand as a normal and necessary alarm response involving the somatic

Published by Sciedu Press and autonomic nervous systems. According to Nørby ${ }^{[32]}$ the autonomic nervous system and stress may affect memory. Weak to moderate emotions may positively affect memory, whereas strong unpleasant emotions negatively affect memory. Emotions therefore affect how students learn and seem to have an important function related to problem-solving as well as memory. ${ }^{[32]}$ No participants in our study were debriefed after stressful situations. This may be because midwives considered the situation to be less acute then the students did and also because of time constraints. However, debriefing can assist students in understanding the situation and may also help them in decision-making. ${ }^{[33,34]}$

In this study, some participants experienced feelings of guilt, particularly in acute situations. The feelings of guilt were most common among participants who had expected to master the situation better. Kaya et al. ${ }^{[35]}$ reported higher scores of guilt and shame among female nursing and midwifery students then among male students. According to Bond, ${ }^{[35]}$ shame arises when individuals believe they have not lived up to their own standards; their performance is either perfect or a total failure, and both of these perceptions inhibit students' ability to learn. Shame affects self-esteem and the ability to learn and interferes with the socialization process in clinical placements. $^{[36]}$

According to Benner, ${ }^{[37]}$ novices depend on procedures, because they have limited experience and it is hard for them to learn if situations are complex and handled in different ways. At first, our participants were outside their comfort zone as nurses and in a new role as midwifery students. This may have affected participants' self-esteem, security and learning capacity. Participants' coping strategies tend to be reduced in the beginning of a placement, especially when acute situations occur.

\subsection{Midwives' influence on learning}

Our grounded theory revealed that the participants' relationships with midwives both facilitate and hinder learning. The relationships could cause stress, which some participants considered to be eustress or strengthening and others considered distress and hampering their learning. This corresponds with the findings in several studies ${ }^{[13,14,16,19]}$ and emphasizes the importance of good relationships between students and mentors.

Our study revealed that midwives who choose learning situations that the participants could master facilitated their learning. Some midwives consciously chosen appropriate situations for participants; others assigned participants tasks randomly as they arose. The participants' emotions and ability to cope varied according to the relationships with 
midwives and the incidents they encountered on the ward. The mentor midwives are also an important role models to support and guide participants in a friendly way, which corresponds with Maxwell et al. ${ }^{[38]}$

Being criticized in front of the women they were helping was distressing and inhibited learning for some participants. They felt humiliated and insecure, their self-esteem was reduced and they felt that the birthing women lost confidence in them. These findings correspond with other studies ${ }^{[39]}$ and demonstrate the vulnerability participants feel in their role. Others also report verbal abuse. ${ }^{[40]}$

\subsection{Academic writing and learning}

The participants experienced the writing assignment early in the clinical studies as a burden. They felt that it took too much time without offering meaningful learning outcomes. Others ${ }^{[41]}$ have confirmed these experiences; midwifery students said that the degree program was more intense and emotionally challenging than expected. Schytt and Waldenström ${ }^{[42]}$ reported that midwifery students in Sweden had little interest in research, which may indicate that the participants focus on the practical requirements in their placements. The writing process is an important tool for reflection and learning and for communicating the learning outcome $\mathrm{e}^{[43]}$ and can result in a deeper approach to learning. ${ }^{[4]} \mathrm{A}$ few of our participants used the writing tasks in adapting to acute situations throughout the entire program, and most of them eventually understood that writing facilitates learning. Writing seemed to process emotions and enhance learning. Writing can also help the students to reflect in a structured way and can help the supervisor in understanding the needs of the individual student. ${ }^{[45]}$

\subsection{Limitations}

The study sample was 10 participants from a Norwegian University College. The relationship between one of the authors (lecturer) and the participants may have influenced the findings. We hoped to minimize this by choosing an open approach such as grounded theory. However, one of the authors being midwife and being familiar with the participants' clinical situations could also be an advantage. The participants could have felt freer to speak. The strengths of this study are the longitudinal design, which followed the cohort over two years and involved different hospitals and low-risk and high-risk labor wards, and the combination of individual and focus-group interviews.

\section{Conclusion}

This grounded theory focusing on the conditions and consequences of midwifery students' learning in labor wards shows that their confidence and degree of self-esteem increased when they were in a trusting relationship with the midwives. This trust did not depend on the duration of the relationship. Being given learning situations they mastered strengthened students' feeling of being suited to become a midwife. Both the relationships and the incidents they encountered in the wards could be sources of eustress or distress for the students. Feedback in general, and debriefing after acute situations in particular, were important in enhancing their learning, because coping in these acute situations is vital for a midwife. Conditions inhibiting learning prevailed when the students felt that they lacked the necessary knowledge or practical skills and when they felt exposed and criticized by the midwife, especially in the labor room. Students stressed the importance of two factors related to their mentors: the midwives need to be proficient and need to appreciate their role in training and educating midwifery students. The University College should offer a formal program offering guidance and training for supervising midwives to establish optimal clinical placement conditions for students learning midwifery.

\section{ACKNOWLEDGEMENTS}

We thank the students for participation in the study and professor Erica Schytt for feedback of this paper.

\section{CONFlicts of InTEREST Disclosure}

The authors declare that there is no conflict interest.

\section{REFERENCES}

[1] Chamberlain M. Challenges of clinical learning for student midwives Midwifery. 1997; 13(2): 85-91. http://dx.doi.org/10.1016/S 0266-6138(97) 90061-9

[2] Thunes S, Sekse Tveit RJ. Midwifery students first encounter with the maternity ward. Nurse Education in Practice. 2015; 15: 243-248. http://dx.doi.org/10.1016/j.nepr.2015.01.012

[3] Davies RM, Atkinson P. Students of midwifery: "doing the obs" and other coping strategies. Midwifery. 1991; 7(3): 113-121. http:
//dx.doi.org/10.1016/S0266-6138(05)80041-5

[4] Cavanagh S, Snape J. Educational sources of stress in midwifery students. Nurse Educational Today. 1997; 17(2): 128-134. http: //dx.doi.org/10.1016/S0260-6917(97)80030-5

[5] Folkman S. Personal Control and Stress and Coping Processes: A Theoretical Analysis. Journal of Personality and Social Psychology 1984; 46(4): 839-852. http://dx.doi.org/10.1037/0022-351 4.46 .4 .839

[6] Ursin H, Eriksen HR. The cognitive activation theory of stress. Psy- 
honeuroendocrinology. 2004; 29(5): 567-592. http://dx.doi.o $\mathrm{rg} / 10.1016 / \mathrm{S} 0306-4530$ (03) 00091-X

[7] Blåka G. Newcomers learning of midwifery practice in labour ward: a socio-cultural perspective. Learning in Health and Social Care. 2006; 5(1): 35-44. http://dx.doi.org/10.1111/j.1473-686 $1.2006 .00113 . \mathrm{x}$

[8] Gilmour C, McIntyre M, McLelland G, et al. Exploring the impact of clinical placement models on undergraduate midwifery students. Women and Birth. 2013; 26(1): e21-e25.

[9] McKenna L, Gilmour C, Biro MA, et al. Undergraduate midwifery students' sense of belongingness in clinical practice. Nurse Education Today. 2013; 33(8): 880-883. PMid:23079722 http://dx.doi.o $\mathrm{rg} / 10.1016 / \mathrm{j}$. nedt .2012 .09 .009

[10] Yearley C. Pre-registration student midwives: "fitting in". British Journal of Midwifery. 1999; 7: 627-631. http://dx.doi.org/10. $12968 / \mathrm{bjom} .1999 .7 .10 .8250$

[11] Begley CM. "Great fleas have little fleas": Irish student midwives' views of the hierarchy in midwifery. Journal of Advanced Nursing. 2002; 38(3): 310-317. http://dx.doi .org/10.1046/j.1365-2 $648.2002 .02181 . \mathrm{x}$

[12] Hunter B. Emotion work and boundary maintenance in hospitalbased midwifery. Midwifery. 2005; 21(3): 253-266. PMid:15967549 http://dx.doi.org/10.1016/j.midw.2004.12.007

[13] Jordan R, Farley C. The confidence to practice Midwifery: Preceptor influence on student self-efficacy. Journal of Midwifery \& Women's Health. 2008; 53: 413-420. PMid:18761294 http: //dx.doi.org/10.1016/j.jmwh.2008.05.001

[14] Licqurish S, Seibold C. Bachelor of midwifery students' experiences of achieving competencies: the role of the midwife preceptor. Midwifery. 2008; 24(4): 480-489. http://dx.doi.org/10.1016/j .midw. 2007.05.001

[15] Bluff R, Holloway I. The efficacy of midwifery role models. Midwifery. 2008; 24(3): 301-309. PMid:17275971 http://dx.doi.o $\mathrm{rg} / 10.1016 / \mathrm{j}$.midw .2005 .02 .008

[16] Armstrong N. Clinical mentors' influence on student midwives' clinical practice. British Journal of Midwifery. 2010; 18(2): 114-123. http://dx.doi.org/10.12968/bjom. 2010.18.2.46411

[17] Hughes A, Fraser D. "There are guiding hands and there are controlling hands": Student midwives experience of mentorship in the UK. Midwifery. 2011; 27: 477-483. PMid:20462677 http: //dx.doi.org/10.1016/j.midw.2010.03.006

[18] Ministry of Education and Research. Rammeplan med Forskrift for Jordmorutdanning [National curriculum and regulations for midwifery education]. Ministry of Education and Research, Oslo. 2004

[19] Brunstad A, Hjälmhult E. Midwifery students' learning experiences in labor wards: A Grounded theory. Nurse Education Today. 2014; 34(12): 1474-1479. http://dx.doi.org/10.1016/j.nedt. 20 14.04 .017

[20] Glaser BG, Strauss AL. The Discovery of Grounded Theory: Strategies for Qualitative Research. New York: Aldine. 1967.

[21] Glaser BG. Theoretical Sensitivity. Advances in the Methodology of Grounded Theory. 4th ed. Mill Valley, CA: Sociology Press; 1978.

[22] Krueger RA, Casey MA. Focus groups: a practical guide for Applied Research. 4th ed. Thousand Oaks, CA: Sage; 2009.

[23] Levett-Jones T, Lathlean J. "Don't rock the boat": nursing students' experiences of conformity and compliance. Nursing Education Today. 2009; 29(3): 342-349. PMid:19056151 http://dx.doi.org/10. 1016/j.nedt. 2008.10.009

[24] Licqurish S, Seibold C, McInerney F. Midwifery students' experiences of achieving competencies for beginning practice. British Journal of Midwifery. 2013; 21(12): 874-885. http://dx.doi.o $\mathrm{rg} / 10.12968 /$ bjom.2013.21.12.874

Published by Sciedu Press
[25] Bairds K. Exploring autonomy in education: preparing student midwives. British Journal of Midwifery. 2007; 15: 400-405. http: //dx.doi.org/10.12968/bjom.2007.15.7.23788

[26] Bandura A. Self-Efficacy Mechanism in Human Agency. American Psychologist. 1982; 37(2): 122-147. http://dx.doi.org/10.10 37/0003-066X.37.2.122

[27] Bandura A. Human agency in Social Cognitive Theory. American Psychologist. 1989; 44(9): 1175-1184. http://dx.doi.org/10. 1037/0003-066X . 44.9.1175

[28] Davies S, Coldridge L. No Man's Land: An exploration of the traumatic experiences of student midwives in practice. Midwifery. 2015; 31: 858-864. PMid:26025871 http://dx.doi.org/10.1016/j .midw.2015.05.001

[29] Begley CM. "Giving midwifery care": student midwives' views of their working role. Midwifery. 2001; 17: 24-34. PMid:11207102 http://dx.doi.org/10.1054/midw.2000.0232

[30] Khajehei M, Ziyadlou S, Hadzic M, et al. The genesis and consequences of stress among midwifery students. British Journal of Midwifery. 2011; 19(6): 379-385. http://dx. doi .org/10.1296 8/bjom.2011.19.6.379

[31] Ursin H, Eriksen HR. Cognitive activation theory of stress (CATS) Neuroscience and Biobehavioral Reviews. 2010; 34(6): 877 881. PMid:20359586 http://dx.doi.org/10.1016/j.neubior ev. 2009.03.001

[32] Nørby S. Emosjoner og læring [Emotions and Learning]. In: Schilhab, T.,S.,S., and Steffensen, B., (Eds), Nervepirrende pedagogikk, en introduksjon til nevrovitenskap [Harrowing pedagogy an introduction to neuroscience]. Kommuneforlaget, Oslo. 2007. 85-109 p.

[33] Young N. An exploration of clinical decision-making among students and newly qualified midwives. Midwifery. 2012; 28(6): 824830. PMid:22079010 http://dx.doi.org/10.1016/j.midw. 20 11.09 .012

[34] Carolan-Olah M, Kruger G, Walter R, et al. Final year students' learning experiences of the Bachelor of Midwifery course. Midwifery. 2014; 30(5): 519-525. PMid:23725754 http://dx.doi .org/10. 1016/j.midw. 2013.04.007

[35] Kaya N, Asti T, Turan N, et al. The feeling of guilt and shame experienced by Nursing and Midwifery students. Nurse Education Today. 2012; 32(6): 630-635. PMid:21920641 http://dx.doi.org/10. $1016 / j$.nedt.2011.08.011

[36] Bond EM. Exposing shame and its effect on clinical nursing education. Journal of Nursing Education. 2009; 48(3): 132140. http://search.proquest. com/docview/203965749?ac countid=15685 PMid:19297963 http://dx.doi.org/10.3928 101484834-20090301-02

[37] Benner P. From Novice to Expert-Excellence and Power in Clinical Nursing Practice. Boston: Addison-Wesley; 1984.

[38] Maxwell E, Black S, Baillie L. The role of the practice educator in supporting nursing and midwifery students' clinical practice learning: An appreciative inquiry. Journal of Nursing Education and Practice. 2015; 5(1): 35-45. http://dx.doi.org/10.5430/jnep.v5n1p3 5

[39] Finnerty G, Pope R. An exploration of student midwives language to describe non-formal learning in professional practice. Nurse Education Today. 2005; 25: 309-315. PMid:15896416 http://dx.doi.o $\mathrm{rg} / 10.1016 / \mathrm{j}$.nedt .2005 .02 .001

[40] Lash AA, Kulakac Ö, Buldukoglu K, et al. Verbal abuse of nursing and midwifery students in clinical settings in Turkey. Journal of Nursing Education. 2006; 45(10): 396-403. Available from: http://search.proquest. com/docview/203964708? accountid=15685 PMid: 17058694 
[41] Green S, Baird K. An exploratory, comparative study investigating attrition and retention of student midwives. Midwifery. 2009; 25(1): 79-87. PMid:18242804 http://dx.doi.org/10.1016/j.midw. 2007.09 .002

[42] Schytt E, Waldenström U. How well does midwifery education prepare for clinical practice? Exploring the views of Swedish students, midwives and obstetricians. Midwifery. 2013; 29(2): 102196. PMid:22265224 http://dx.doi.org/10.1016/j.midw. 20 11.11 .012

[43] Lillejord S, Dysthe O. Productive learning practice a theoretical discussion based on two cases. Journal of Education and Work.
2008; 21(1): 75-89. http://dx.doi.org/10.1080/136390808 01957154

[44] Erlander J, Harrington K, Norton L, et al. Complex skills and academic writing: a review of evidence about the type of learning required to meet core assessment criteria. Assessment \& Evaluation in Higher Education. 2006; 1: 71-90. http://dx. doi .org/10.1080 /02602930500262379

[45] Persson E, Kvist L, Ekelin M. Analysis of midwifery students written reflections to evaluate progression in learning during clinical practice at birthing units. Nurse Education in Practice. 2015; 15: 134-140. PMid:25661056 http://dx.doi.org/10.1016/j.nep r.2015.01.010 